\title{
MICRORREGIÃO 17 DE PRESIDENTE PRUDENTE SP - ESTUDO DE CASO SOBRE AS ÁREAS PÚBLICAS
}

Rafaella Rúbia do Prado Barbosa', Yasmin Miranda Perosso', Marcos Norberto Boin², Mayara Pissutti Albano ${ }^{1}$, Sibila Corral de Arêa Leão Honda ${ }^{1}$, Fabrícia Moraes Fernandes Borges ${ }^{1}$

${ }^{1}$ Universidade do Oeste Paulista - UNOESTE, Curso de Arquitetura e Urbanismo, Presidente Prudente - SP. ${ }^{2}$ Universidade Federal da Grande Campo Grande, Campo Grande, MS. E-mail: fabricia.arquiteta@gmail.com

\section{RESUMO}

O processo de urbanização brasileiro ocasionou o aumento da cidade ilegal, fruto de invasões e crescimento descontrolado sem devido planejamento, culminando em áreas com deficiência de espaços livres públicos. Esses ambientes são de extrema importância para as cidades, seja no aspecto social, ambiental, sanitário e até mesmo estético. Apoiado nesses fatos, o presente artigo tem como objetivo identificar, levantar e mapear as áreas livres públicas da Microrregião administrativa 17 da cidade de Presidente Prudente-SP, e verificar seus usos atuais. Para isso, a metodologia usada será baseada em pesquisas bibliográficas e documentais, buscando um aprofundamento no assunto, e o levantamento físico-territorial para posterior mapeamento de tais áreas.

Palavras-chave: Áreas livres; áreas públicas, urbanização, microrregião 17, Presidente Prudente.

\section{MICROREGION 17 OF PRESIDENTE PRUDENTE SP - CASE STUDY ABOUT PUBLIC AREAS}

\begin{abstract}
The Brazilian urbanization process has caused the increase of the illegal city, due to invasions and uncontrolled growth without the necessary planning, resulting in areas with deficiency of public open spaces.Theseenvironments are extremely important to the cities, as social, environmental, sanitary and aesthetic aspects. Supported by these facts, this paper has the objective to identify, gather and map the public open areas of the administrative Microregion 17 of the city of Presidente Prudente-SP, and verify their current uses.Thus, the methodology applied has been based on bibliographical and documental researches, focusing a deepening in the subject, and physic-territorial survey to subsequent mapping of the areas analysed.
\end{abstract}

Keywords: Open areas; public areas; urbanization; microregion 17; Presidente Prudente. 


\section{INTRODUÇÃO E JUSTIFICTIVA}

O espaço urbano, em seu aspecto físico,é composto por espaços edificados e, em menor quantidade, por espaços livres. (SÁ CARNEIRO \& MESQUITA; 2000). Magnoli (1986), defineespaços livres urbanos como espaços livres de edificação, como os jardins públicos ou privados, ruas e avenidas, praças e parques, matas, mangues e praias urbanas, ou simples vazios urbanos. Formam um sistema com relações de conectividade e complementaridade, constituindo um sistema complexo.

Os papéis exercidos pelos espaços livres públicos podem ser funcionais, como a circulação urbana, sociais e culturais através do convívio público,bem como ambientais na conservação e requalificação ambiental, sendo importantes elementos na estrutura das cidades, não devendo ser negligenciados (FREITAS, s/d) .

O processo de urbanização do Brasil na segunda metade do século XX, apresentou intensificação (SANTOS, 2005). Ocorreu um enorme movimento de construção de cidade legal e ilegal, e juntamente com a necessidade de moradia, há necessidades como saneamento básico, transportes, saúde, educação, espaços de lazer, etc.

Infelizmente, sabe-se que o crescimento urbano não ocorreu de maneira adequada, e que, a ausência de um planejamento prévio, reforça a ocupação do território de forma não apropriada (MARICATO, 2001), dificultando a implantação de áreas urbanas para formar um sistema de espaços livres públicos coeso e completo, que atenda de maneira ampla e coerente toda a cidade (MENNHE e COELHO, 1999).

Com o processo de urbanização e crescimento das cidades os espaços livres públicos se tornaram cada vez mais necessários para a qualidade ambiental, sanitária e para a qualidade de vida para a população residente nas urbes, além do caráter estético atribuídos ao lugar (CUNHA, 2003).

Em 1979 a Lei Federal n.6.766 estruturou legalmente o processo de parcelamento, delegando ao Município, o controle do uso, ocupação e parcelamento do solo urbano,bem como a responsabilidade de planejamento e gestão da área da cidade. A partir de então, deve ser gerado um estoque de terras destinadas à implantação do sistema de áreas verdes, áreas institucionais e sistema viário que tentará fornecer às cidades brasileiras uma revisão de suas formas de ocupação e distribuição dos espaços livres.

Partindodo exposto, busca-se aprofundar os conhecimentos a respeito das áreas livres públicas na Microrregião Administrativa 17 da cidade de Presidente Prudente - SP, verificando eventuais alterações de uso, mapeando-as e identificando seus atuais usos e ocupação. 
A divisão de Microrregião Administrativas foi uma maneira da Prefeitura Municipal subdividir a malha urbana de Presidente Prudente, não oficialmente, para possibilitar e facilitar os levantamentos da própria Prefeitura e do Ministério Público, relativas a falta de áreas públicas aprovadas legalmente e com usos alterados, conforme consta no Inquérito Civil - IC № MP : 14.0720.0000322/2.011-1.

A Microrregião 17 está inserida na região periférica da cidade, a sul do quadrilátero central, e é composta pelos seguintes bairros: Jardim Brasília, Jardim Itatiaia, Jardim Itatiaia prolongamento, Jardim Novo Planalto, Jardim Planaltina, Jardim Santa Marta, Jardim Santa Marta II, Jardim São Domingos, Jardim São Pedro, Vila Brasil, Vila Delger, Vila Flores, Vila Líder, Vilar Líder Prolongamento, Vila Paulo Roberto. Os bairros são de classe média e classe média baixa.

O objetivo do presente trabalho é apresentar o levantamento da atual situação dos espaços livres dos bairros que compõem a Microrregião 17, mapeando as áreas aprovadas legalmente como espaços livres - áreas institucionais, áreas de lazer, e verificando sua real utilização na atualidade e, desta forma, identificar possível incompatibilidade com a legislação federal,estadual e municipal.

\section{METODOLOGIA}

O presente trabalho foi dividido em três etapas de procedimentos metodológicos, sendo eles: levantamento bibliográfico, pesquisa documental, e levantamentos físico territoriais urbanísticos das áreas livres públicas e áreas institucionais da cidade de Presidente Prudente - SP .

Através do levantamento bibliográfico, pôde-se identificar e levantar produções na área de conhecimento, assim como pesquisas realizadas sobre áreas livres públicas e áreas institucionais, bem como outros assuntos relacionados ao tema.

Numa segunda etapa, foi realizada pesquisa documental - políticas, ações voltadas às áreas livres públicas e áreas institucionais, legislação municipal, estadual e federal relacionadas ao parcelamento, uso e ocupação do solo urbano, mapeamentos de aspectos como: estrutura urbana municipal, localização das referidas áreas na malha urbana, uso atual dessas áreas.

A etapa seguinte da pesquisa foi a de levantamentos físico territoriais das áreas livres públicas e das áreas institucionais da cidade de Presidente Prudente-SP. Tais levantamentos tiveram como objetivo verificar aspectos relativos ao uso e ocupação do solo, equipamentos e serviços, a localização e a conformidade dos usos aos quais foram destinadas. Os mapeamentos foram realizados através do software Spring. 


\section{RESULTADOS}

Para fins de pesquisa, foram analisados três tipos de áreas públicas: áreas institucionais, áreas livres e áreas verdes (Fig.1).

Considerou-se área verde "a de propriedade pública ou particular, delimitada pela prefeitura, com o objetivo de implantar ou preservar arborização e ajardinamento, visando manter a ecologia e resguardar as condições ambientais e paisagísticas" (GEIGERet al., 1975, apud NUCCI, 2001).Para área livre, adota-se a seguinte definição "[...]aquela livre de construção, de propriedade pública ou privada. " (LIMA, 1994), e áreas institucionais, segundo o artigo $2^{\circ}$ da lei complementar n.154(2008) "são as áreas a serem doadas ao município e destinadas à construção de escolas, postos de saúde, creches, prédios administrativos municipais, delegacias e outros prédios públicos".

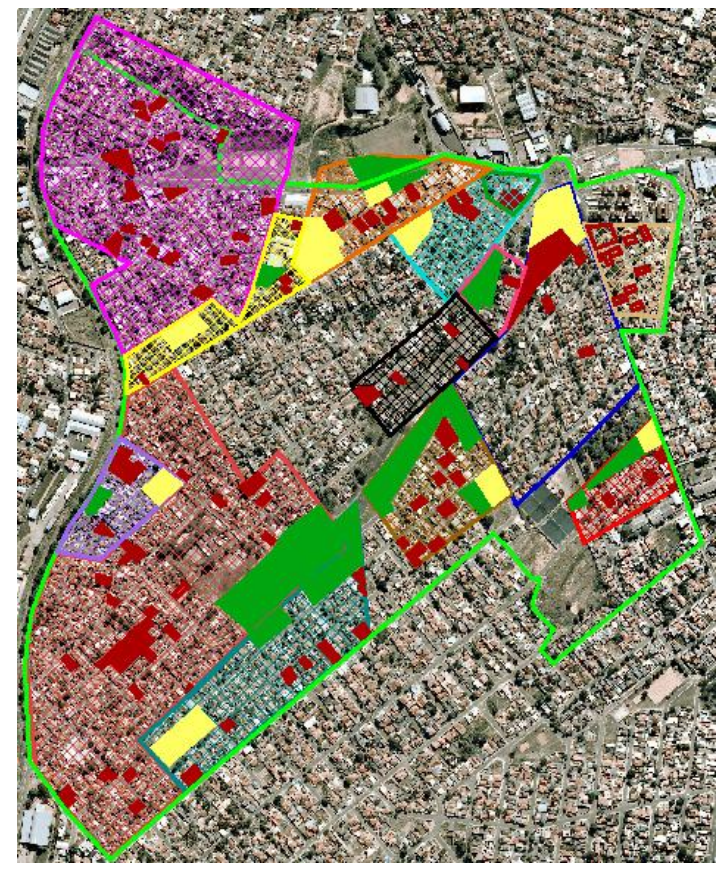

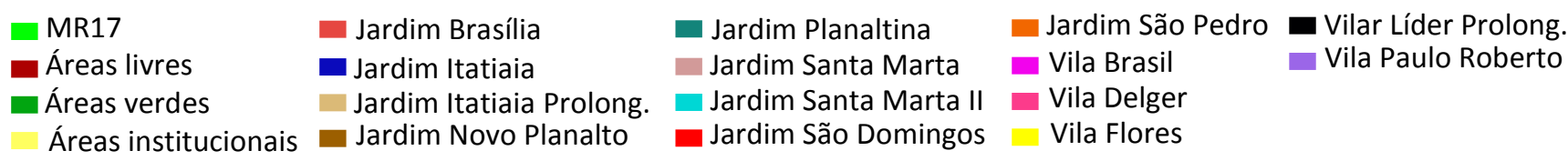

Figura 1. Microrregião 17 e suas áreas públicas.

Fonte: Autoras (2015).

Os doze bairros que compõem a microrregião foram avaliados individualmente mediante a metodologia adotada, obtendo os dados presentes na tabela 1. 
Tabela 1. Dados obtidos pela pesquisa

\begin{tabular}{|c|c|c|c|}
\hline BAIRROS & $\begin{array}{l}\text { ÁREAS } \\
\text { LIVRE }\end{array}$ & ÁREAS VERDES & ÁREA INSTITUCIONAL \\
\hline Jardim Brasília & 24 & $\begin{array}{l}2 \text { (ocupada por um campo de futebol e uma } \\
\text { área de preservação ocupada pelo Parque do } \\
\text { Povo localizado no bairro. }\end{array}$ & 1 (ocupada pela Fatec) \\
\hline Jardim Planaltina & 7 & $\begin{array}{l}2 \text { (uma se encontra anexa ao campo de futebol } \\
\text { do Jardim Brasília e a outra é ocupada pelo } \\
\text { Parque do Povo do bairro e é parcialmente } \\
\text { loteada) }\end{array}$ & $\begin{array}{l}1 \text { (ocupada pela Escola } \\
\text { Municipal João Bohac) }\end{array}$ \\
\hline Jardim Novo Planalto & 9 & $\begin{array}{l}2 \text { (uma área verde de preservação parcialmente } \\
\text { ocupada pelo Parque do Povo e a outra } \\
\text { desocupada }\end{array}$ & $\begin{array}{l}1 \text { (encontra-se } \\
\text { parcialmente ocupada } \\
\text { pelo sistema viário e } \\
\text { parcialmente livre. }\end{array}$ \\
\hline Jardim Itatiaia & 4 & - & $\begin{array}{l}8 \text { (ocupadas por Posto } \\
\text { Policial, Telefônica, } \\
\text { Escola Aziz Felipe e ruas) }\end{array}$ \\
\hline $\begin{array}{l}\text { Jardim Itatiaia } \\
\text { prolongamento }\end{array}$ & 8 & - & - \\
\hline $\begin{array}{l}\text { Jardim Santa Marta } \\
\text { (encontra-se localizado } \\
\text { dentro do bairro Jardim } \\
\text { Santa Marta II) } \\
\end{array}$ & 1 & e & - \\
\hline Jardim Santa Marta II & 3 & $\begin{array}{l}\text { (Foi analisado que no planejamento desse } \\
\text { bairro, o bairro Jardim Santa Marta foi } \\
\text { totalmente considerado como área verde (área } \\
\text { de lazer), porém foi doada à Prudenco para no } \\
\text { local ser implantado o Programa Nosso Teto, } \\
\text { atualmente essa área encontrasse ocupada por } \\
\text { residências e uma parte está livre. }\end{array}$ & $\begin{array}{l}1 \text { (ocupada pela Unidade } \\
\text { de Saúde do Jardim São } \\
\text { Pedro) }\end{array}$ \\
\hline Jardim São Domingos & 4 & $\begin{array}{l}2 \text { (uma área verde ocupada irregularmente pela } \\
\text { Igreja Batista e o Centro Comunitário São Bento } \\
\text { e a outra é livre) }\end{array}$ & $\begin{array}{l}1 \text { (ocupada } \\
\text { irregularmente por uma } \\
\text { igreja Evangélica e duas } \\
\text { residências }\end{array}$ \\
\hline $\begin{array}{l}\text { Jardim São Pedro } \\
\text { (De acordo com o mapa } \\
\text { cedido pela prefeitura } \\
\text { os limites do bairro } \\
\text { excedem os limites da } \\
\text { MR17) }\end{array}$ & 6 & $\begin{array}{l}1 \text { (pertencente ao sistema de recreio e ocupada } \\
\text { parciamente por uma Unidade Básica de Saúde } \\
\text { e pelo sistema viário) }\end{array}$ & $\begin{array}{l}1 \text { (ocupada pela Escola } \\
\text { Municipal Prof. } \underline{\text { a }} \\
\text { Carmem Pereira Delfim. }\end{array}$ \\
\hline $\begin{array}{l}\text { Vila Brasil } \\
\text { (De acordo com o mapa } \\
\text { cedido pela prefeitura } \\
\text { os limites do bairro } \\
\text { excedem os limites da } \\
\text { MR17) }\end{array}$ & 18 & $\begin{array}{l}1 \text { (área verde doada à prefeitura que concedeu } \\
\text { a permissão da implantação da Casa da } \\
\text { Amizade, de sistema viário e sistema de lazer, } \\
\text { porém também foi invadida por residências } \\
\text { irregulares) }\end{array}$ & - \\
\hline Vila Delger & 1 & $\begin{array}{l}1 \text { (área verde de preservação que foi } \\
\text { desapropriada para a implantação de uma } \\
\text { galeria e uma Avenida, atualmente encontra-se } \\
\text { o Parque do Povo do bairro) }\end{array}$ & - \\
\hline Vila Flores & 4 & 1 (área verde ocupada pela Praça São Pedro) & $\begin{array}{l}\text { 1(ocupada pela Unidade } \\
\text { de merenda }\end{array}$ \\
\hline Vila Líder & \multicolumn{3}{|c|}{$\begin{array}{l}\text { (Não foi possível obter os limites do bairro Vila Líder pois de acordo com a prefeitura } \\
\text { Municipal de Presidente Prudente e o } 2 \text { o oficial de registro de imóveis da comarca de } \\
\text { Presidente Prudente - SP, alguns mapas de bairro foram perdidos ao longo do tempo, } \\
\text { assim as locações das áreas verdes, livres e institucionais não foram feitas.) }\end{array}$} \\
\hline $\begin{array}{l}\text { Vilar Líder } \\
\text { Prolongamento }\end{array}$ & 4 & $\begin{array}{l}1 \text { (área verde de preservação que foi } \\
\text { desapropriada para a implantação de galeria e }\end{array}$ & - \\
\hline
\end{tabular}




\begin{tabular}{|l|l|l|l|}
\hline & & $\begin{array}{l}\text { onde atualmente se encontra o Parque do Povo } \\
\text { do bairro. }\end{array}$ & \\
\hline Vila Paulo Roberto & 2 & $\begin{array}{l}\text { 2 (uma está ocupada irregularmente pela Escola } \\
\text { Edna Carnelos e a outra está loteada } \\
\text { irregularmente) }\end{array}$ & 1 \\
\hline
\end{tabular}

Fonte: Autores (2015).

\section{CENÁRIO DE UMA FRAÇÃO URBANA}

A microrregião 17, é formada por bairros de classe média e classe média baixa. Esta região apresenta alguns problemas que se destacam em meio a tantos que podem ocorrer no cenário urbano, dentre os quais, descacam-se principalmente a existência de alguns lotes e edificações que descumprem as determinações legais.

De acordo com a lei n.154 (2008), o parcelamento de solo não poderá ser feito em:

$$
\begin{aligned}
& \text { IV - em terrenos onde as condições geológicas não são } \\
& \text { aconselháveisàedificação; } \\
& \text { V - em áreas de preservação permanente, de preservação de mananciais } \\
& \text { hídricos e fundos de vales, assim definidos em Lei. }
\end{aligned}
$$

O terceiro parágrafo do artigo $12^{\circ}$ da lei n.6.766 complementa "É vedada a aprovação de projeto de loteamento e desmembramento em áreas de risco definidas como não edificáveis, no plano diretor ou em legislação dele derivada."

Na microrregião 17, objeto de estudo do presente trabalho, foram encontradas residências dentro de áreas de preservação ambiental e loteamentos executados sobre fundo de vale (Fig. 2). A situação atual desta área está fortemente relacionada com a expansão urbana da cidade de Presidente Prudente, pois conforme afirma Pioli, (2006) as ocupações irregulares são consequencias da economia crescimento urbano desordenado, da concentração de renda e da postura omissa do Estado.

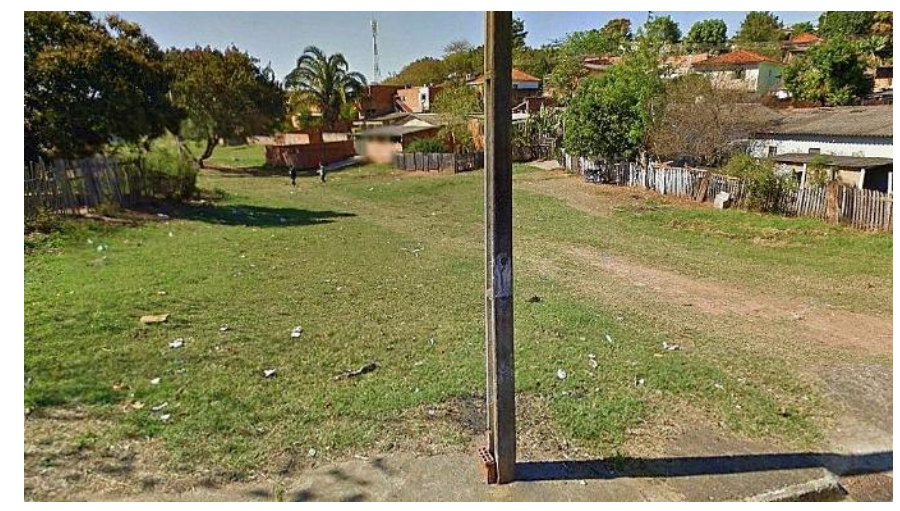

Figura 2: Loteamentos em fundo de vale

Fonte: Autoras (2015). 
Marisco (2003, p. 03) afirma que :

A consolidação de processos de informalidade na ocupação urbana se traduz pelo uso e ocupação do solo urbano às margens das normas urbanísticas, ou seja, que não correspondem na prática o que determinam os instrumentos urbanísticos de regulação do espaço urbano [...]

Concretizando assim um padrão de urbanização seletivo e excludente, ou seja, se estabelecem dois padrões paralelos de reprodução da cidade: uma parte da cidade se constrói obedecendo aos princípios legais estabelecidos pela legislação urbanística, e outra que se constrói à revelia da lei (MARISCO, 2003).

\section{CONSIDERAÇÕES FINAIS}

Conclui-se que a microrregião apresenta várias irregularidades. Faltam informações e algumas são apresentadas de formas variadas, fora da realidade atual e fugindo do controle do poder público. Atualmente a situação encontrada é a falta de estrutura em toda a MR17, o que é quase impossível se reverter pela falta de espaços livres.

Para tal são necessários novos instrumentos de gestão, novas práticas políticas que correspondam às novas transformações que promovam alterações na promoção de serviços públicos e na regulamentação do uso do solo urbano.

\section{REFERÊNCIAS}

BRASIL.Estatuto da Cidade. Lei complementarn.10.257 de 10/07/2001. Regulamenta os artigos 182 e 183 da Constituição Federal de 1988.

BRASIL. Lei n.154, de 10 de janeiro de 2008.Dispõe sobre a Lei de Parcelamento do Solo para FinsUrbanos e dá outrasprovidências.

BRASIL. Lei n.6.766, de 19 de dezembro de 1979. Dispõe sobre o parcelamento do solo urbano e dá outras providências.

CUNHA, Rita Dionde Araújo. Os espaços públicos abertos e as leis de uso e ocupação do solo: uma questão de qualidade para ambientes sustentáveis. III Enecs - Encontro Nacional sobre Edificações e Comunidades Sustentáveis. 2003.

FREITAS, J.C. Bens Públicos de Loteamentos e sua Proteção Legal. Revista de Direito Imobiliário. n.46, pp.185-200. s/d. Disponível em: www.mpba.mp.br/atuacao/ceama/material/doutrinas/arborizacao/bens_publicos_de_loteament os_sua_protecao_legal.pdf. Acesso em 01 out 2013. 
LIMA, Ana Maria Liner Pereira.Problemas de utilização na conceituação de termos como espaços livres, áreas verdes e correlatos.In. II Congresso Brasileiro de Arborização Urbana, 1994, São Luís/MA. Anais... 1994, p. 539-553.

MAGNOLI, Miranda, M. O parque no desenho urbano. In:TURKIENICZ, B. \& MALTA, M. Desenho urbano, Anais do II SEDUR, São Paulo, PINI/ FINEP, CNPq, 1986. p. 111- 120.

MARICATO, Ermínia.Brasil cidades: alternativas para a crise urbana.Petrópolis, RJ: Vozes, 2001.

MARISCO, Luciane Maranha de Oliveira. A norma e o fato: abordagem analítica da segregação sócio-espacial e exclusão social a partir dos instrumentos urbanísticos. 2003. Tese (Doutorado) Faculdade de Ciência e Tecnologia, Universidade Estadual Paulista Julio de Mesquita Filho, Presidente Prudente.

MENNHE, M. H. \& COELHO, A. M. Características do sistema de parques públicos urbanos da cidade de São Paulo. In: ENTAC, 8, 2000, Salvador. ANAIS, Salvador: ANTAC., 2000. 8 p. CD-ROM. Seção artigos.

MINISTÉRIO PÚBLICO ESTADUAL. Inquérito Civil - IC NNo MP: 14.0720.0000322/2.011-1.

$\mathrm{NUCCl}$, João Carlos. Qualidade ambiental \& adensamento urbano: um estudo de Ecologia e Planejamento da Paisagem aplicado ao distrito de Santa Cecília (MSP).São Paulo: Humanitas/ FFLCH-USP, 2001.

PIOLI, M.S.M.B; ROSSIN, A.C. O meio ambiente e aocupaçãoirregulardo espaço urbano. Revista Brasileira deCiências Ambientais - número 3. 2006. p.41.

SÁ CARNEIRO, A. R.; MESQUITA, L. B. Espaços Livres do Recife. Recife: Prefeitura da Cidade do Recife. Universidade Federal de Pernambuco, 2000.

SANTOS, Milton. A urbanização brasileira.5.ed.São Paulo: Universidade de São Paulo,2005. 